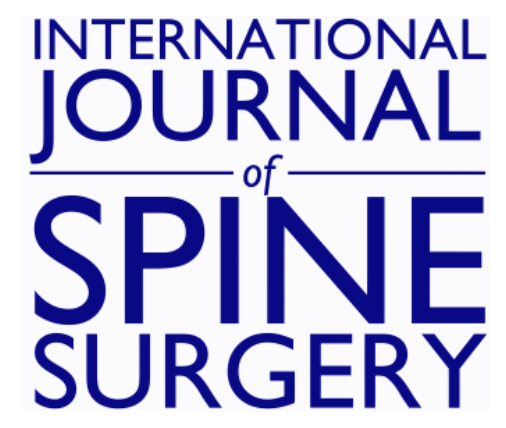

\title{
Quantitative Gross and CT measurements of Cadaveric Cervical Vertebrae (C3 - C6) as Guidelines for the Lateral mass screw fixation
}

Santosh K. Sangari, Thomas E. Heinneman, Mathew S. Conti, Paul-Michel F. Dossous, David J. Dillon, Apostolos J. Tsiouris, Se Young Pyo, Estomih P. Mtui and Roger Härtl

Int J Spine Surg 2016, 10 ()

doi: https://doi.org/10.14444/3043

http://ijssurgery.com/content/10/43

This information is current as of April 26, 2023.

Email Alerts Receive free email-alerts when new articles cite this article. Sign up at:

http://ijssurgery.com/alerts


2397 Waterbury Circle, Suite 1,

Aurora, IL 60504, Phone: +1-630-375-1432 


\section{Quantitative Gross and CT measurements of Cadaveric Cervical Vertebrae (C3 - C6) as Guidelines for the Lateral mass screw fixation}

Santosh K. Sangari, MBBS, Master of Surgery (Anatomy), 1 Thomas E. Heinneman, MD,2,3 Mathew S. Conti, 2 Paul-Michel F. Dossous, MD,2,4 David J. Dillon, PhD, ${ }^{2}$ Apostolos J. Tsiouris, MD, 5 Se Young Pyo, MD, 6,7 Estomih P. Mtui, MD,1 Roger Härtl, MD ${ }^{6}$

1 Program in Anatomy and Body Visualization, Department of Radiology, Weill Cornell Medicine, New York, NY, 2Weill Cornell Medical College, New York, NY, ${ }^{3}$ Otolaryngology - Head and Neck Surgery, UCLA Health, Los Angeles, CA, ${ }^{4}$ Department of Orthopedic Surgery, Albany Medical Center Hospital, Albany, NY, ${ }^{5}$ Department of Radiology, Neuroradiology section, New York-Presbyterian Hospital, Weill Cornell Medicine, New York, NY, ${ }^{6}$ Brain and Spine Center, NewYork-Presbyterian Hospital, Weill Cornell Medicine, New York, NY, ${ }^{7}$ Department of Neurosurgery, College of Medicine, Inje University, Busan Paik Hospital, Busan Korea

\section{Abstract}

\section{Background}

Lateral mass screw fixation is the treatment of choice for posterior cervical stabilization. Long or misdirected screws carry a risk of injury to spinal nerve roots or vertebral artery. This study was aimed to assess the gross anatomic and CT measurements of typical cervical vertebrae for the selection of lateral mass screws.

\section{Methods}

Dimensions of the articular pillars were measured on 1) Dry cervical vertebrae with Vernier calipers and 2) Multiplanar reformations of CT scans of the same vertebrae with Viewer software package. The data was statistically evaluated.

\section{Results}

The transverse diameter of the articular pillars with Vernier calipers varied from 6.0 to $15.4 \mathrm{~mm}$ (mean=10.5 $\mathrm{mm} \pm$ $1.5)$ and on CT scans ranged from $8.2-16.1 \mathrm{~mm}$ (mean=11.6 $\mathrm{mm} \pm 1.4)$. The antero-posterior diameter, an estimate of the screw length by Roy-Camille technique varied from 3.9 to $12.7 \mathrm{~mm}$ (mean=8.6 $\mathrm{mm} \pm 1.6$ ) by Vernier calipers and from 6.4 to $13.3 \mathrm{~mm}$ (mean=9.1 \pm 1.2 ) on CT scans. The oblique AP diameter, an estimate of screw length by Magerl method varied from 10.8 to $20.3 \mathrm{~mm}$ (mean=14.9 $\mathrm{mm} \pm 1.8$ ) by Vernier calipers and from 11.4 to $19.3 \mathrm{~mm}$ (mean $=14.5 \mathrm{~mm} \pm 1.7$ ) on CT. The CT measurements for height, transverse and AP diameter of the articular pillars were $0.5-1.0 \mathrm{~mm}$ larger than dimensions by Vernier calipers. No statistically significant difference was observed between the caliper and CT measurements for the oblique AP diameter.

\section{Conclusion}

CT measurements of the articular pillars may slightly overestimate the desired screw length selected by spine surgeons when compared to actual anatomy. Although means of the articular pillars correspond to the screw lengths used, substantial number of observations below $10 \mathrm{~mm}$ for Roy-Camille trajectory and below $14 \mathrm{~mm}$ for Magerl trajectory requires careful preoperative planning and intra-operative confirmation to avoid long/misdirected lateral mass screws.

KEYWORDS: LATERAL MASS SCREWS, ARTICULAR PILLAR, TYPICAL CERVICAL VERTEBRA, POSTERIOR FIXATION

VOLUME 10 ARTICLE 43 DOI: 10.14444/3043

\section{Introduction}

Fixation of the cervical spine can be performed by different techniques. Posterior wiring of cervical spine was first described for treatment of cervical spine fractures. ${ }^{1}$ In 1970, Camille and coworkers introduced posterior plate screw fixation into the artic- ular pillars in the cervical spine. ${ }^{2,3}$ Later Magerl designed a new technique using hook plates for improved stable internal fixation. ${ }^{4,5}$ In contrast, anterior decompression and fusion is performed by combined plate and bone fusion on patients with myelopathy when the pathological source of cord compression is chiefly located anteriorly. ${ }^{6}$ 
The close proximity of the vertebral artery and the cervical nerve roots to the articular pillars in the cervical vertebrae makes them vulnerable to injury during spine fixation. ${ }^{7,8,9}$

In a retrospective study of lateral mass plating for posterior cervical spine fusion with bicortical purchase resulted in direct vertebral artery injury in 5.8\% of patients and direct nerve root injury in $17.4 \%$ of patients. ${ }^{10}$ In another study, complications of posterior rod-screw fixation by the Magerl technique included radiculopathy in $4 \%$ of patients, loss of alignment in $1 \%$ and cerebrospinal fluid leak in $1 \%$ with no evidence of spinal cord or vertebral artery injury. ${ }^{11}$ In a third study, the posterior screw fixation of the cervical and upper thoracic spine resulted in radiculopathy in $5.1 \%$, facet violation in $1.3 \%$, spinal cord injury in $2.6 \%$ of patients with no incidence of vertebral artery injury. ${ }^{12}$

In order to improve the rigidity of the posterior fixation and to limit the number of levels that need to be included in a fusion, posterior cervical stabilization with lateral mass screws has been advocated.

The use of lateral mass screws for traumatic injuries of the cervical spine is associated with excellent maintenance of alignment and minimum complications. ${ }^{13}$

The choice of lateral mass screw length and screw positioning is highly dependent on the proper determination of the dimensions of the cervical articular pillars. In particular, the antero-posterior diameter of the articular pillar corresponds to the screw length for the Roy-Camille trajectory. ${ }^{3}$ The oblique anteroposterior diameter of the articular pillar corresponds to the screw length according to the Magerl trajectory. ${ }^{4}$ The literature describing the dimensions of the cervical articular pillars is limited.

This study was designed to quantify the measurements of the articular pillars of cadaveric C3-C6 vertebrae available in the lab. Since CT has been the standard way of knowing the anatomy and dimensions of the lateral masses of the cervical vertebral column, the CT scans of the same set of cervical vertebrae were undertaken and the same measurements were done to determine if these two techniques produce similar results. The width, height, anteroposterior (AP) diameter representing Roy-Camille trajectory ${ }^{3}$ and oblique antero-posterior (OAP) diameter corresponding to the Magerl trajectory ${ }^{4}$ were measured on the articular pillars of the cervical vertebrae and on the CT scans. The relationship between the gross anatomical and CT measurements would serve as important parameters for the spine surgeons and may help to decrease the rate of complications during the lateral mass screw fixation.

\section{Materials and Methods}

The study was conducted on the random sample of eighty-one dry individual typical cervical vertebrae (C3 - C6) available in the Gross Anatomy lab. The age, sex and race of the individuals from whom these vertebrae were derived was not known.

The observations were recorded by the same group of investigators both by Vernier calipers and on CT viewer software and were also monitored regularly.

Measurements were taken on the right and left articular pillars of dry cervical vertebrae (Figure 1A) by using digital stainless steel Vernier calipers with 0.01 $\mathrm{mm}$ accuracy from VWR (Van Waters and Rogers) Global Laboratory Supply and Distribution Company (Figure 1B). The blades of the Vernier calipers were expanded and contracted twice for every measurement and a mean of the two measurements was recorded. The calipers were brought back to zero before taking another measurement.

Helical CT scans of the same set of cervical vertebrae were also analyzed. Imaging was performed on a GE, HD Discovery 750 CT scanner (Milwaukee, Wisconsin) with a slice thickness of $0.625 \mathrm{~mm}$. The measurements were done on multiplanar reformations (MRP) generated on a GE Advantage Workstation v. 4.3 utilizing the Volume Viewer software package (Figure 2).

The following dimensions of the articular pillars were measured by Vernier calipers (Figure 1A, Figure 1B) and on multiplanar reformations (MRP) generated on a GE Advantage Workstation v. 4.3 utiliz- 
ing the Volume Viewer software package (Figure 2):

1. Vertical height of the articular pillar (from upper end of the superior articular facet to the lower end of the inferior articular facet),

2. Smallest transverse diameter in the middle of the articular pillar,

3. Antero-posterior (AP) diameter from the middle of the raised elevation on the back of the articular pillar (midpoint on the posterior surface of the articular pillar) to the anterior margin of the pillar at the root of the transverse process (Roy-Camille technique),

4. Oblique antero-posterior (OAP) diameter, paral-

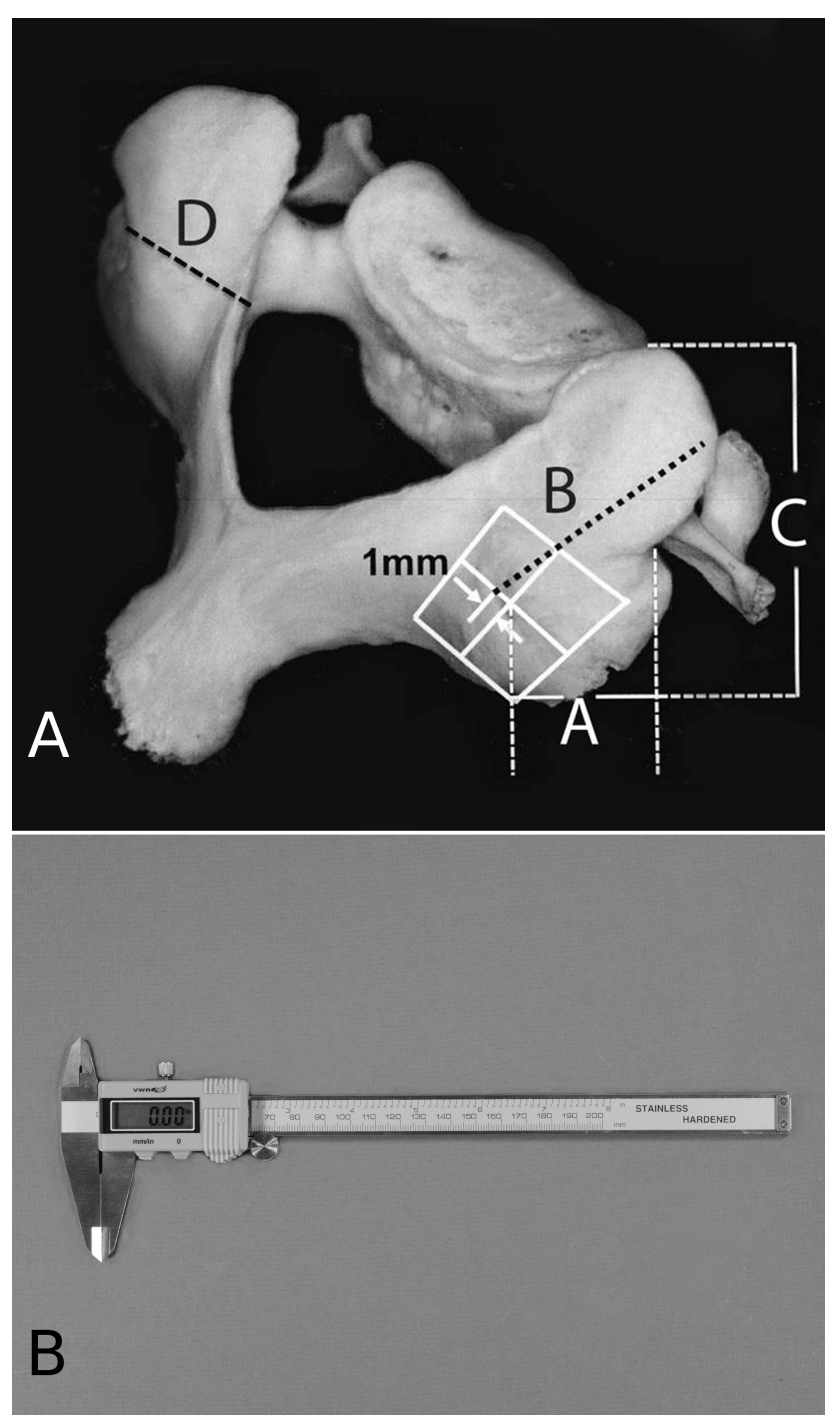

Fig. 1A. Typical cervical vertebra showing various measurements of the Articular pillar by Vernier calipers: $A=$ Antero-posterior diameter

(Roy-Camille method), B = Oblique antero-posterior diameter (Magerl method), $C=$ Height of the articular pillar, $D=$ Transverse diameter. Fig. 1B. VWR (Van Waters and Rogers) stainless steel digital Vernier calipers used to measure various dimensions on dry cervical vertebrae. lel to the superior articular facet, from $1 \mathrm{~mm}$ medial to the middle of the raised elevation on the back of the articular pillar (1mm medial to the midpoint on the posterior surface of the articular pillar) to the lateral upper end of the superior articular facet (Magerl technique). It is worth noting that Magerl technique is more popular among spine surgeons.

\section{Statistical Methods}

The measurements obtained by the Vernier calipers were statistically compared with CT measurements. Unpaired t-tests were used to assess differences between Vernier caliper and CT measurements, while paired t-tests were used to evaluate differences between right and left articular pillars and correlation between the measured dimensions in the same vertebra. In all instances, p-value $<0.05$ (two-sided) was considered statistically significant. All analysis were conducted in Stata Version 11 and Microsoft Excel 2010.

\section{Results}

Table 1 summarizes the various diameters of the articular pillars of the typical cervical vertebrae (C3 C6) with the help of Vernier calipers and CT software. The mean transverse diameter of the right/left
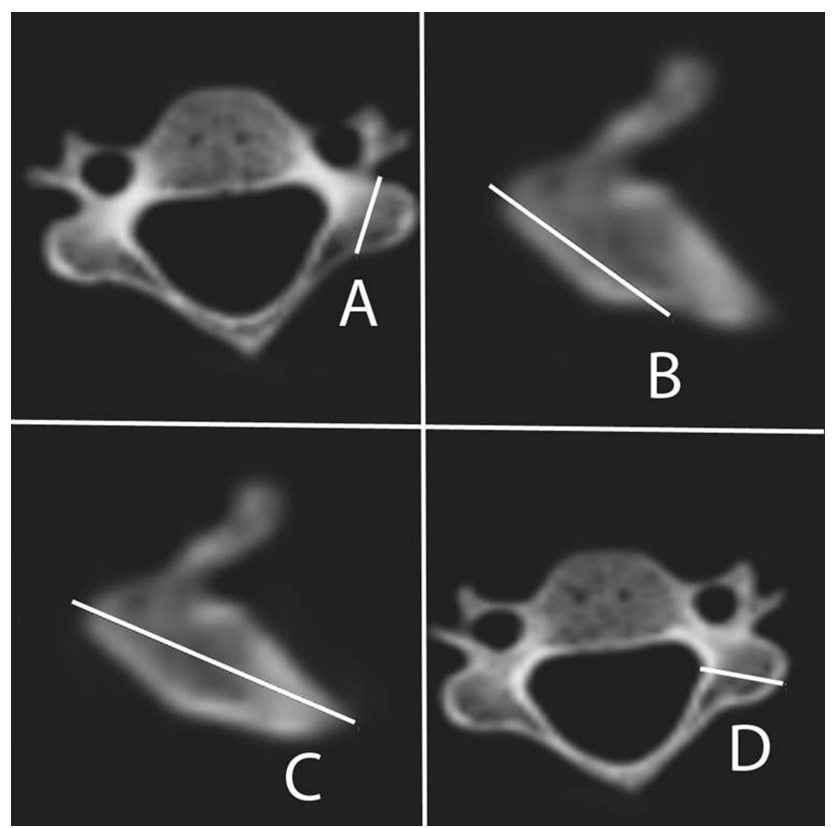

Fig. 2. Typical cervical vertebra showing various measurements of the Articular pillar by CT scan software: $\mathrm{A}=$ Antero-posterior diameter (Roy-Camille method), B = Oblique antero-posterior diameter (Magerl method),$C=$ Height of the articular pillar,$D=$ Transverse diameter. 
side articular pillars with the help of Vernier calipers was $10.6 \mathrm{~mm} \pm 1.5$ (range: $7.5-15.4 \mathrm{~mm}$ ) $/ 10.3 \mathrm{~mm} \pm$ 1.3 (range: $6.0-13.2 \mathrm{~mm}$ ) respectively. The average mean transverse diameter was $10.5 \pm 1.5 \mathrm{~mm}$ (range: 6.0 to $15.4 \mathrm{~mm}$ ). On CT scans, the mean transverse diameter of the right/left articular pillars was 11.5 $\mathrm{mm} \pm 1.4$ (range: $8.2-16.1 \mathrm{~mm}$ ) $/ 11.7 \mathrm{~mm} \pm 1.4$ (range: $9.4-14.9 \mathrm{~mm}$ ). The average mean transverse diameter was $11.6 \mathrm{~mm} \pm 1.4$ (range: $8.2-16.1 \mathrm{~mm}$ ) (Table 1).

The AP diameter is representative of the screw length by Roy-Camille method. With the help of Vernier Calipers, the mean AP diameter of the right/ left articular pillar was $8.7 \mathrm{~mm} \pm 1.5$ (range: 4.4 $12.7 \mathrm{~mm}$ )/ $8.5 \mathrm{~mm} \pm 1.6$ (range: $3.9-11.7 \mathrm{~mm}$ ) respectively. The average mean AP diameter of the articular pillars was $8.6 \mathrm{~mm} \pm 1.6$ (range: $3.9-12.7 \mathrm{~mm}$ ).

On the CT scans, the mean AP measurements of the articular pillars right/left side were $9.1 \mathrm{~mm} \pm 1.2$ (range: $6.4-11.5 \mathrm{~mm}$ ) and $9.2 \mathrm{~mm} \pm 1.2$ (range: 7.0 $13.3 \mathrm{~mm}$ ) respectively. The average AP diameter of the articular pillars varied from $6.4 \mathrm{~mm}$ to $13.3 \mathrm{~mm}$

\begin{tabular}{|c|c|c|c|c|c|c|c|c|}
\hline & \multicolumn{2}{|c|}{$\begin{array}{r}\text { Transverse di- } \\
\text { ameter }(\mathrm{mm})\end{array}$} & \multicolumn{2}{|c|}{ Height (mm) } & \multicolumn{2}{|c|}{$\begin{array}{r}\text { Antero- } \\
\text { posterior di- } \\
\text { ameter } \dagger \\
(\mathrm{mm})\end{array}$} & \multicolumn{2}{|c|}{$\begin{array}{r}\text { Oblique } \\
\text { Antero- } \\
\text { posterior di- } \\
\text { ameter } \$(\mathrm{~mm})\end{array}$} \\
\hline & $\begin{array}{r}\text { Mean } \\
\text { (SD) }\end{array}$ & Range & $\begin{array}{r}\text { Mean } \\
\text { (SD) }\end{array}$ & Range & $\begin{array}{r}\text { Mean } \\
(\mathrm{SD})\end{array}$ & Range & $\begin{array}{r}\text { Mean } \\
\text { (SD) }\end{array}$ & Range \\
\hline \multicolumn{9}{|c|}{ Right Articular pillars } \\
\hline $\begin{array}{l}\text { Vernier } \\
\text { caliper }\end{array}$ & $\begin{array}{r}10.6 \\
(1.5)\end{array}$ & $\begin{array}{l}7.5- \\
15.4\end{array}$ & $\begin{array}{l}20.0 \\
(2.3)\end{array}$ & $\begin{array}{r}14.2- \\
25.5\end{array}$ & $\begin{array}{r}8.7 \\
(1.5)\end{array}$ & $\begin{array}{r}4.4- \\
12.7\end{array}$ & $\begin{array}{l}15.0 \\
(1.8)\end{array}$ & $\begin{array}{r}11.9- \\
20.3\end{array}$ \\
\hline $\begin{array}{l}\text { CT soft- } \\
\text { ware }\end{array}$ & $\begin{array}{r}11.5 \\
(1.4)\end{array}$ & $\begin{array}{r}8.2- \\
16.1\end{array}$ & $\begin{array}{r}21.1 \\
(1.9)\end{array}$ & $\begin{array}{r}17.1- \\
25.4\end{array}$ & $\begin{array}{r}9.1 \\
(1.2)\end{array}$ & $\begin{array}{r}6.4- \\
11.5\end{array}$ & $\begin{array}{r}14.3 \\
(1.8)\end{array}$ & $\begin{array}{r}11.5- \\
19.3\end{array}$ \\
\hline \multicolumn{9}{|c|}{ Left Articular pillars } \\
\hline $\begin{array}{l}\text { Vernier } \\
\text { caliper }\end{array}$ & $\begin{array}{r}10.3 \\
(1.3)\end{array}$ & $\begin{array}{l}6.0- \\
13.2\end{array}$ & $\begin{array}{l}20.1 \\
(2.0)\end{array}$ & $\begin{array}{r}14.6- \\
24.5\end{array}$ & $\begin{array}{r}8.5 \\
(1.6)\end{array}$ & $\begin{array}{r}3.9 \\
-11.7\end{array}$ & $\begin{array}{l}14.8 \\
(1.8)\end{array}$ & $\begin{array}{r}10.8- \\
19.6\end{array}$ \\
\hline $\begin{array}{l}\text { CT soft- } \\
\text { ware }\end{array}$ & $\begin{array}{r}11.7 \\
(1.4)\end{array}$ & $\begin{array}{r}9.4- \\
14.9\end{array}$ & $\begin{array}{r}20.9 \\
(1.9)\end{array}$ & $\begin{array}{r}16.9- \\
25.6\end{array}$ & $\begin{array}{r}9.2 \\
(1.2)\end{array}$ & $\begin{array}{r}7.0- \\
13.3\end{array}$ & $\begin{array}{r}14.7 \\
(1.7)\end{array}$ & $\begin{array}{r}11.4- \\
18.7\end{array}$ \\
\hline \multicolumn{9}{|c|}{ All Articular pillars } \\
\hline $\begin{array}{l}\text { Vernier } \\
\text { caliper }\end{array}$ & $\begin{array}{r}10.5 \\
(1.5)\end{array}$ & $\begin{array}{r}6.0- \\
15.4\end{array}$ & $\begin{array}{l}20.1 \\
(2.1)\end{array}$ & $\begin{array}{r}14.2- \\
25.5\end{array}$ & $\begin{array}{r}8.6 \\
(1.6)\end{array}$ & $\begin{array}{r}3.9- \\
12.7\end{array}$ & $\begin{array}{r}14.9 \\
(1.8)\end{array}$ & $\begin{array}{r}10.8- \\
20.3\end{array}$ \\
\hline $\begin{array}{l}\text { CT soft- } \\
\text { ware }\end{array}$ & $\begin{array}{l}11.6 \\
(1.4)\end{array}$ & $\begin{array}{r}8.2- \\
16.1\end{array}$ & $\begin{array}{l}21.0 \\
(1.9)\end{array}$ & $\begin{array}{r}16.9- \\
25.6\end{array}$ & $\begin{array}{r}9.1 \\
(1.2)\end{array}$ & $\begin{array}{r}6.4- \\
13.3\end{array}$ & $\begin{array}{r}14.5 \\
(1.7)\end{array}$ & $\begin{array}{r}11.4- \\
19.3\end{array}$ \\
\hline
\end{tabular}

$($ mean $=9.1 \mathrm{~mm} \pm 1.2)($ Table 1$)$.

There was no statistically significant difference between measurements of the right and left side articular pillars. The box and whisker plot showed outliers with transverse diameter as low as $6 \mathrm{~mm}$ and AP diameter as low as $3.9 \mathrm{~mm}$ (Figure 3 ).

The mean height of the Right/Left articular pillar with the help of Vernier Calipers was $20.0 \mathrm{~mm} \pm 2.3$ (range from $14.2 \mathrm{~mm}$ to $25.5 \mathrm{~mm}$ ) and $20.1 \mathrm{~mm} \pm 2.0$ (range from $14.6 \mathrm{~mm}$ to $24.5 \mathrm{~mm}$ ) respectively. The average height of the articular pillar varied from 14.2 $\mathrm{mm}$ to $25.5 \mathrm{~mm}$ with a mean of $20.1 \mathrm{~mm} \pm 2.1$. On CT scans, the mean height of the Right/Left articular pillar was $21.1 \mathrm{~mm} \pm 1.9$ (range from $17.1 \mathrm{~mm}$ to $25.4 \mathrm{~mm}$ ) and $20.9 \mathrm{~mm} \pm 1.9$ (range from $16.9 \mathrm{~mm}$ to $25.6 \mathrm{~mm}$ ) respectively. The average height of the articular pillar varied from $16.9 \mathrm{~mm}$ to $25.6 \mathrm{~mm}$ with a mean of $21.0 \mathrm{~mm} \pm 1.9$ (Table 1 ).

The unpaired t-test showed statistically significant difference between the Vernier caliper and CT measurements for the transverse, AP diameters and the height of the articular pillar (Table 2, p-value <.001). The CT measurements were $0.5-1.0 \mathrm{~mm}$ higher as compared to the measurements by Vernier calipers.

The oblique antero-posterior (OAP) diameter of the articular pillar is representative of the screw length by Magerl method. With the help of Vernier Calipers, the mean OAP diameter of the right/left articular pillar was estimated to be $15.0 \mathrm{~mm} \pm 1.8$ (range: $11.9 \mathrm{~mm}-20.3 \mathrm{~mm}$ ) $/ 14.8 \pm 1.8$ (range: 10.8

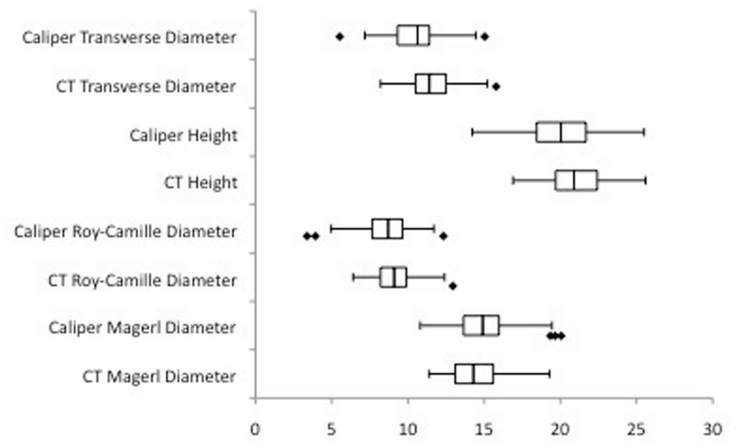

Fig. 3. Box-and-whisker plot showing various dimensions of the articular pillars in millimeters $(\mathrm{mm})$. Each plot shows the median, quantification of data and outliers. 
$\mathrm{mm}-19.6 \mathrm{~mm}$ ) respectively. The average OAP diameter of the articular pillar varied from $10.8 \mathrm{~mm}$ to $20.3 \mathrm{~mm}$ with a mean of $14.9 \mathrm{~mm} \pm 1.8$. The mean OAP diameter of the right/left articular pillar on CT scans was $14.3 \mathrm{~mm} \pm 1.8$ (range: $11.5 \mathrm{~mm}-19.3 \mathrm{~mm}$ )/ $14.7 \mathrm{~mm} \pm 1.7$ (range: $11.4 \mathrm{~mm}-18.7 \mathrm{~mm}$ ) respectively. The average OAP diameter of the articular pillar varied from $11.4 \mathrm{~mm}$ to $19.3 \mathrm{~mm}$ with a mean of 14.5 $\mathrm{mm} \pm 1.7$ (Table 1).

The comparison between the Vernier caliper and CT measurements by unpaired t-test showed no statistically significant difference for the oblique anteroposterior diameter (Magerl technique).

Although there was a wide variation between the AP, transverse, OAP diameters and Vertical height of the right and left articular pillars by Vernier calipers and CT measurements, there was no statistically significant difference between the right and left articular pillars (Table 2).

The CT measurements also showed smaller standard deviations for all the measurements when compared with the measurements by Vernier calipers (Table 2).

Again, results support previous CT studies, which is the current practice.

\section{Discussion}

The anatomical relationship of the vertebral artery and cervical pedicles and the importance of preoperative evaluation of the cervical anatomy have been described in prior publication. ${ }^{14}$

\begin{tabular}{|c|c|c|c|c|}
\hline & $\begin{array}{r}\text { Transverse } \\
\text { diameter ( } \mathrm{p} \\
\text { value) }\end{array}$ & $\begin{array}{r}\text { Height } \\
\text { (p val- } \\
\text { ue) }\end{array}$ & $\begin{array}{r}\text { Antero-posterior } \\
\text { diameter } \dagger(\mathrm{p} \\
\text { value })\end{array}$ & $\begin{array}{r}\text { Oblique antero- } \\
\text { posterior diameter } \\
\text { ( } \mathrm{p} \text { value) }\end{array}$ \\
\hline $\begin{array}{l}\text { Right } \\
\text { Articular } \\
\text { pillars }\end{array}$ & $<0.001$ & $<0.001$ & 0.04 & 0.02 \\
\hline $\begin{array}{l}\text { Left Ar- } \\
\text { ticular } \\
\text { pillars }\end{array}$ & $<0.001$ & 0.01 & 0.004 & 0.76 \\
\hline $\begin{array}{l}\text { All Ar- } \\
\text { ticular } \\
\text { pillars }\end{array}$ & $<0.001$ & $<0.001$ & $<0.001$ & 0.06 \\
\hline
\end{tabular}

The articular pillars have been used for many years successfully for placement of lateral mass screws for cervical spine fixation. The lateral mass screws in cervical spine provide superior biomechanical stability over the posterior wiring techniques and can be implemented even when the spinous process and lamina are deficient. ${ }^{15-20}$

This technique reduces the need for halo immobilization and allows earlier neck mobilization. ${ }^{21,22,23}$ However, lateral mass screws may be associated with injury risk of exiting spinal nerve roots, vertebral artery or caudal facet injury caused by long/misdirected screws. ${ }^{11,12,24,25,26}$ The posterior screw fixation of the cervical and upper thoracic spine in seventyeight patients resulted in radiculopathy in four patients, facet violation in one patient, iatrogenic foraminal stenosis in two patients with no incidence of vertebral artery injury. ${ }^{12}$ The Roy-Camille and Magerl are the two most commonly used techniques for the cervical articular pillar fixation (Figure 4). The literature shows that there was significantly lower error rate in Roy-Camille technique with regard to correct placement and nerve root injury, whereas the Magerl screws fared better with respect to the facet violation..$^{24,25}$ In comprehensive study of 100 patients, screw placement using a technique similar to Magerl resulted in radiculopathy in $4 \%$ of cases with no spinal cord or vertebral artery injuries. ${ }^{11}$

Some surgeons may prefer bicortical purchase for lateral mass screw fixation, but the literature has
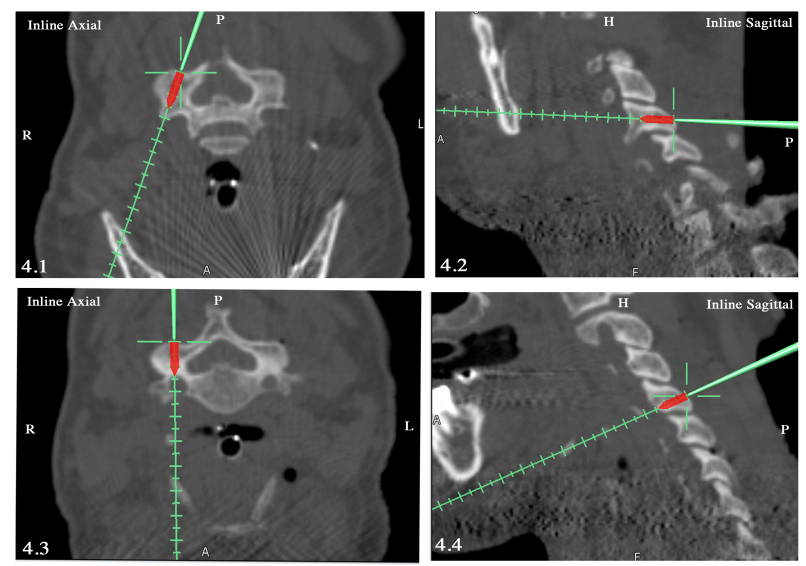

Fig. 4. Most commonly used articular pillar screw trajectories: Magerl technique $(4.1,4.2)$ and Roy-Camille technique $(4.3,4.4)$. 
shown debatable or no statistically significant difference in the pullout force between unicortical versus bicortical screw fixation. ${ }^{10,26}$ Some authors observed $5.8 \%$ of direct vertebral artery injury and $17.4 \%$ of direct nerve root injury with the bicortical screws when compared to unicortical lateral mass screws. ${ }^{10}$ Other authors reported nerve root injury in $8.3 \%$ of cases using Roy-Camille technique, 5.6\% by Magerl technique and 3.3\% by Kim's method (similar to Magerl technique) and Facet violation of $16.7 \%$ in all the three techniques with bicortical purchase. ${ }^{26}$

There is limited literature available on dimensions of the articular pillars in the cervical spine..$^{25,27,28,29}$ Most surgical papers have reported the screw length in Roy-Camille and Magerl techniques by their experience and empiric estimation or measurement from imaging studies. To our knowledge, this is the first paper that directly compares the dimensions of the articular pillars by Vernier calipers and modern volumetric CT imaging software on the same set of dry cervical vertebrae available in the lab.

\section{Transverse diameter}

The CT width of the lateral mass in cervical spine has been reported to range from 10.10 to $14.64 \mathrm{~mm}$ with a mean of $11.92 \mathrm{~mm} \pm 0.96 .{ }^{27}$ The literature also shows the comparison between the transverse diameter of the articular pillar in patients with developmental canal stenosis and patients with acquired canal stenosis. ${ }^{28}$ The lateral mass width was greater in males when compared to the females $(11.1 \pm 1.3$ $\mathrm{mm}$ in male and $10.0 \pm 1.0 \mathrm{~mm}$ in female) at the level of C 3 vertebra and there is a gradual progression in size of the articular pillar in lower cervical vertebrae $(12.8 \pm 1.2$ in male and $11.1 \pm 1.4 \mathrm{~mm}$ in female $)$ at the level $\mathrm{C} 6$ vertebra. The mean transverse diameter varied from $11.7 \pm 1.5 \mathrm{~mm}$ at the level of $\mathrm{C} 3$ to $12.2 \pm$ $1.4 \mathrm{~mm}$ at the level of $\mathrm{C} 6$ in patients with developmental canal stenosis, whereas in patients with acquired canal stenosis, the transverse diameter varied from $12.3 \pm 1.5 \mathrm{~mm}$ at $\mathrm{C} 3$ to $12.8 \pm 1.8 \mathrm{~mm}$ at $\mathrm{C} 6$ vertebra. ${ }^{28}$

No comparisons have been made in the measurements on right /left articular pillars in the above studies. The present work shows variations between the transverse diameters of right and left articular pillars both by Vernier calipers and CT measurements in the vertebrae studied as seen in Table 1, but no statistically significant differences were found between the right and left side measurements.

It is important to note that as expected, the mean transverse measurements in the present study $(10.5 \pm$ $1.5 \mathrm{~mm}$ by Vernier calipers/ $11.6 \pm 1.4 \mathrm{~mm}$ by CT scan) are much smaller than the measurements available for the patients with developmental/acquired canal stenosis.

The average width of the lateral mass in the CT scans has been reported to range from 10.10 to 14.64 mm with a mean of $11.92 \mathrm{~mm} \pm 0.96^{29}$ and the CT measurements taken in the present study almost correspond with the observations in the literature.

The box and whisker plot (Figure 3) shows most of the transverse dimensions of the articular pillars between -1 and +1 SD. It is important to note that the outliers were observed by Vernier calipers with transverse diameter of the articular pillars, as small as 6 $\mathrm{mm}$. The variance in the transverse diameter of the articular pillars is of particular importance because this dimension is used by the surgeon for the appropriate screw thickness for articular pillar fixation using the Roy-Camille technique.

\section{The Antero-Posterior Diameter (Roy-Camille Trajectory)}

The AP diameter of the articular pillar corresponds to the length of the screw in Roy-Camille technique. Although there is no literature available on the dimensions of the AP diameter of the articular pillar, the mean screw length in lateral mass screw fixation by Roy-Camille method was $11.7 \mathrm{~mm} \pm 1.5$ in male and $11.0 \mathrm{~mm} \pm 1.5$ in female at $\mathrm{C} 3$ vertebra and progressively increased to $12.4 \pm 1.5$ in male and $11.4 \pm$ 1.4 in female at C6 vertebra. ${ }^{25}$

In spite of the variations observed between right and left side AP diameters in the present study, there was no statistically significant difference between the two side measurements. It is important to note that the mean AP diameter (Table 1 ) is comparatively smaller in the present study $(8.6 \mathrm{~mm} \pm 1.6$ by Vernier calipers and $9.1 \mathrm{~mm} \pm 1.2$ by CT scan software) as 
compared to the screw length estimated in the literature. Furthermore, the box and whisker plot shows most of AP dimensions of the articular pillars studied to be less than $10 \mathrm{~mm}$ both in Caliper and in CT scans and also outliers less than $5 \mathrm{~mm}$ (Figure 3). The smaller AP diameter of the articular pillar estimated in the present study is important while choosing the length of the lateral mass screws by RoyCamille method and furthermore the substantial number of observations and outliers in the lower range should be kept in mind by the surgeon for the selection of screws for the Roy-Camille technique. The transverse, AP diameters and the height of the articular pillars showed statistically significant difference between CT and Vernier caliper measurements ( $\mathrm{p}$ value $<0.001$ ). The mean height, transverse and AP measurements of the articular pillars by CT scans were $0.5-1.0 \mathrm{~mm}$ higher as compared to the measurements by Vernier calipers. This difference may be due to technical errors, as gross measurements with Vernier calipers are done over the bony points of the vertebra and the CT dimensions were performed on oblique reformatted images. Our reported difference of $0.5-1.0 \mathrm{~mm}$ suggests that the screw length chosen for Roy-Camille technique should be $1 \mathrm{~mm}$ smaller than the AP dimension of the articular pillar estimated in a CT scan, to avoid penetration of the ventral bone cortex during surgery and damage to the vertebral artery and nerve roots. Therefore, preoperative and intraoperative CT and radiographic assessments would be helpful in estimating the length of the screws to be used in these patients by Roy-Camille technique.

\section{The Oblique Antero-posterior Diameter (Magerl Trajectory)}

The OAP diameter of the articular pillar corresponds to the length of the screw in Magerl technique. . $25,29,30^{2}$ The length of the screw has been reported to be 14.0 $\mathrm{mm} \pm 1.7$ at $\mathrm{C} 3$ vertebra by Magerl technique and progressively increased to $15.6 \mathrm{~mm} \pm 2.1$ at $\mathrm{C} 6$ vertebra in male, whereas it was $13.2 \mathrm{~mm} \pm 1.7$ at $\mathrm{C} 3$ vertebra and progressively increased to $14.0 \mathrm{~mm} \pm 2.1$ at C6 vertebra in female. ${ }^{25}$ The literature showed CT depth of the Magerl screw trajectory on the lateral mass of the cervical vertebral column to vary from $10.36 \mathrm{~mm}$ to $15.34 \mathrm{~mm}$ with a mean of $12.83 \mathrm{~mm} \pm$ 1.28. ${ }^{29}$ Other investigators reported mean screw path length of $14 \mathrm{~mm}$ for the Magerl technique from C3 to C6 vertebrae. ${ }^{31}$

The present study did not show statistically significant difference between the CT and caliper measurements while estimating the length of the screw by Magerl method. Although the mean OAP diameter in the present study $(14.9 \mathrm{~mm} \pm 1.8$ with Vernier calipers and $14.5 \mathrm{~mm} \pm 1.7$ with CT scan software) more or less corresponds to the observations made in the literature, the box and whisker plot shows a substantial number of observations less than $14 \mathrm{~mm}$ (Figure 3), which should be kept in mind by the surgeon to avoid penetration of ventral cortex, while inserting lateral mass screws by Magerl technique. The penetration of the ventral cortex can be detected by the axial CT scans. An intraoperative CT and/or oblique radiographs are important for evaluating the screw placement and encroachment of the intervertebral foramen and should be routinely performed prior to the completion of surgery., ${ }^{7,8}$

An important observation made in the present study was that the CT measurements showed smaller standard deviations for all the measurements when compared with the measurements by Vernier calipers (Table 2) suggesting better reproducibility. This supports the current standard of using CT scans to approximate the dimensions of cervical spine.

\section{Conclusion}

This study provides true anatomical and CT based measurements of the $\mathrm{C} 3-\mathrm{C} 6$ vertebral articular pillars to assist surgeons in the proper selection of articular pillar screw for spinal fixation. The mean height, AP and transverse CT dimensions were statistically 0.5 $1.0 \mathrm{~mm}$ higher as compared to the gross anatomical measurements by Vernier calipers ( $p$ value $<.001$ ), whereas the OAP diameter did not show statistically significant difference between the two measurements. This difference may be a due to technical differences between the caliper measurements on the bony points and CT software measurements on oblique reformatted images. The CT measurements showed smaller standard deviations for all the measurements when compared with the measurements by Vernier calipers (Table 2). This suggests that the 
CT measurements are more reproducible. Therefore, careful preoperative and intraoperative radiographic and/or CT imaging during surgery are recommended. Although the means of the articular pillars correspond to the screw lengths used by the spine surgeons, the substantial number of observations in the present study below $10 \mathrm{~mm}$ for RoyCamille trajectory and below $14 \mathrm{~mm}$ for Magerl trajectory should to be kept in mind by the surgeon to avoid complications created by long misdirected lateral mass screws.

\section{Limitations of the study}

1. The technical difficulty identifying $\mathrm{C} 3 / \mathrm{C} 4 / \mathrm{C} 5 /$ C6 vertebrae in a random sample of dry vertebrae available in our anatomy lab.

2. The records for the details of the age, sex, race and built of the individuals from whom the vertebrae were derived was not available.

3. The CT measurements and caliper measurements were not directly paired at the specimen level. This would have allowed for a more direct assessment of agreement between the two sets of measurements, either by Bland-Altman methodology or alternative methodologies to assess agreement (e.g., intraclass correlation coefficient).

4. The dimensions for C7 vertebra were not measured, as transpedicle screws are more commonly advocated for $\mathrm{C} 7, \mathrm{~T} 1$ and $\mathrm{T} 2$ vertebrae.

It requires further studies taking the age, sex, race, built into consideration and to harvest the intact cervical vertebral columns from the cadavers available in the lab to develop parameters for individual cervical vertebral levels.

\section{References}

1. Hadra BE. Wiring the vertebrae as a mean of immobilization in fractures and Pott's disease. Transactions of American Orthopedic Association 4: 1891; 206. (Quoted in Clin Orthop 1975;112:4-8).

2. Roy-Camille R, Saillant G: Actualités de chirurgie orthopédique de l'Hôpital RaymondPoincarré. Vol. 8, Fractures du Rachis Cervical. Edited by R.Judet, Paris, Masson \& Cie, 1970;175-195.
3. Roy-Camille R, Saillant G, Mazel C. Internal fixation of the unstable cervical spine by a posterior osteosynthesis with plate and screw. In: Cervical spine Research Society (ed.). The Cervical Spine. 2nd ed. Philadelphia: JB Lippincott; 1989: p 390-403.

4. Magerl F, Grob D, Seeman P. Stable dorsal fusion of the cervical spine (C2-Th1) using hook plates, Cervical spine l. edited by $\mathrm{P}$ Kehr, A Weider, Springer-Verlag, 1987.

5. Jeanneret B, Magerl F, Ward EH, et al. Posterior stabilization of the cervical spine with hook plates. Spine 1991;16(3): S56-S63.

6. Brown JA, Havel P, Ebraheim N et al. Cervical stabilization by plate and bone fusion. Spine: 1988;13(3):236-240.

7. Ebraheim NA, An HS, Xu R, et al. The quantitative anatomy of the cervical nerve groove and the intervertebral foramen. Spine 1996; 21(14):1619-1623.

8. Ebraheim NA, Hoeflinger MJ, Salpietro B, et al. Anatomical considerations in posterior plating of the cervical spine. J Orthop Trauma 1991; 5:196-199.

9. Ebraheim NA, Xu R, Yeasting RA. The location of vertebral artery foramen and its relation to posterior lateral mass screw fixation. Spine 1996; 21(11):1291-1295.

10. Seybold FA, Baker JA, Criscitiello AA, et al. Characteristics of unicortical and bicortical lateral mass screws in the cervical spine. Spine 1999; 24(22):2397-2403.

11. Deen HG, Nottmeier EW, Reimer R. Early complications of posterior rod-screw fixation of the cervical and upper thoracic spine. Neurosurg 2006; 59(5):1062-1068.

12. Heller JG, Silcox DH, Sutterlin CE. Complications of posterior cervical plating. Spine 1995;

20(22):2442-2448.

13. Pateder DB, Carbone JJ. Lateral mass screw fixation for cervical spine trauma: associated complications and efficacy in maintaining alignment. Spine J 2006; 6(1):40-43.

14. Tomasino A, Parikh K, Koller H, Zink W, Tsiouris J, Steinberger J, Härtl R. 2010. The vertebral artery and the cervical pedicle: morphometric analysis of a critical neighbourhood. J Neurosurg: Spine 13, 1:52-60.

15. Gill K, Paschal S, Corin J, et al. Posterior plating of the cervical spine. Biomechanical comparison of 
different posterior fusion techniques. Spine 1988; 13(7):813-816.

16. Coe JD, Warden KE, Sutterlin CE, et al. Biomechanical evaluation of cervical spine stabilization methods in human cadaveric model. Spine 1989; 14:1122-1131.

17. Kotani Y, Cunningham BW, Abumi K, et al. Biomechanical analysis of cervical stabilization systems. An assessment of transpedicular screw fixation in cervical spine. Spine 1994;19:2529-2539.

18. Heller JG, Estes BT, Zaouali M, et al. Biomechanical study of screws in the lateral masses: variables affecting pull- out resistance. J Bone Joint Surg Am 1996; 78:1315-1321.

19. Adam MS, Crawford NR, Chamberlain RH, et al. Biomechanical comparison of anterior cervical plating and combined anterior/lateral mass plating. Spine J 2001 1:166-170.

20. Do Koh Y, Lim TH, Won You J, et al. A biomechanical comparison of modern anterior and posterior plate fixation of the cervical spine. Spine 2001; 26:15-21.

21. Levine AM, Mazel C, Roy-Camille R. Management of fracture separations of the articular mass using posterior cervical plating. Spine 1992; 17(10S): S447-S454.

22. Wellman BJ, Follett KA, Traynelis VC. Complications of posterior articular mass plate fixation of the subaxial cervical spine in 43 consecutive patients. Spine 1998; 23(2):193-200.

23. Sekhon LH. Posterior cervical lateral mass screw fixation: analysis of 1026 consecutive screws in 143 patients. J Spinal Disord Tech 2005;18:297-303. 24. Heller JG, Carlson GD, Abitbol JJ, et al. Anatomical comparison of the Roy-Camille and Magerl techniques for screw placement in the lower cervical spine. Spine 1991; 16(10):S552- S557.

25. Stemper BD, Marawar SV, Yoganandan N, et al. Quantitative anatomy of subaxial cervical lateral mass: An analysis of safe screw lengths for RoyCamille and Magerl techniques. Spine 2008; 33(8):893-897.
26. Baek JW, Park DM, Kim DH. Comparative analysis of three different cervical lateral mass screw fixation techniques by complications and bicortical purchase: Cadaveric study. J Korean Neurosurg Soc 2010; 48:193-198.

27. Punjabi MM, Duranceau J, Goel V, et al. Cervical human vertebrae: Quantitative three-dimensional anatomy of the middle and lower regions. Spine 1991;16:861-869.

28. Miyazaki M, Takita C, Yoshiiwa T, et al. Morphological analysis of the cervical pedicles, lateral masses and laminae in developmental canal stenosis. Spine 2010; 35(24): E1381-E1385.

29. Mohamed E, Zidan I, Moaz A, et al. Lateral mass fixation in subaxial cervical spine: Anatomic review. Global Spine J 2012;2:39-46.

30. Ann HS, Gordin R Renner K. Anatomical considerations for plate-screw fixation of the cervical spine. Spine 1991;16(10):S548-551.

31. Cho JI and Kim DH. Comparative analysis of cervical lateral mass screw insertion among three techniques in the Korean population by quantitative measurements with reformatted 2D CT scan images: J Korean Neurosurg Soc 2008; 44(3):124-130.

\section{Disclosures \& COI}

The authors declare that there is no conflict of interests regarding the publication of this paper.

\section{Corresponding Author}

Dr. Santosh K. Sangari, Program in Anatomy and Body Visualization, Department of Radiology, Weill Cornell Medicine, A-518 B, 1300 York Avenue, New York, NY 10065. sks2005@med.cornell.edu.

Published 20 December 2016.

This manuscript is generously published free of charge by ISASS, the International Society for the Advancement of Spine Surgery. Copyright @ 2016 ISASS. To see more or order reprints or permissions, see http://ijssurgery.com. 